
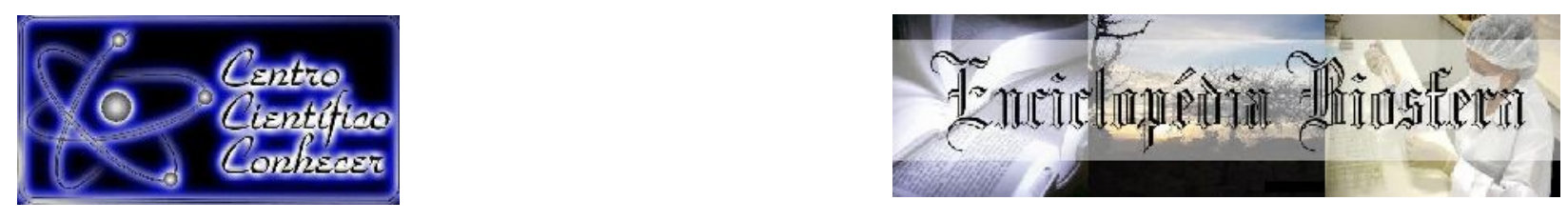

\title{
INIBIÇÃO DE PLANTAS INVASORAS PELA FRAÇÃO ACETATO DE ETILA DO SORGO
}

Crystal de Resende Gomes ${ }^{1}$; Aline Maria Orbolato Gonçalves-Zuliani ${ }^{2}$; Anny Rose Mannigel $^{2}$; Letycia Lopes Ricardo ${ }^{3}$; Graciene de Souza Bido ${ }^{2}$

1. Graduada em Agronomia, Centro Universitário Cesumar - Unicesumar, MaringáPR, Brasil.

2. Docente, Centro Universitário Cesumar - Unicesumar, Maringá-PR, Brasil. Email: gsbido@hotmail.com

3. Docente, Universidade Federal do Paraná - UFPR, Palotina-PR, Brasil.

Recebido em: 06/04/2019 - Aprovado em: 10/06/2019 - Publicado em: 30/06/2019 DOI: 10.18677/EnciBio_2019A79

\begin{abstract}
RESUMO
O amendoim-bravo (Euphorbia heterophylla L.) e o picão-preto (Bidens pilosa L.) estão entre as principais plantas invasoras da cultura de soja (Glycine max (L.) Merril). O método de controle mais utilizado é o químico, através de herbicidas, muitas vezes aplicados indiscriminadamente com consequente impacto ambiental, bem como elevado custo. Contudo, interações alelopáticas promovidas por metabólitos secundários liberados por cobertura vegetal, podem caracterizar um meio alternativo de combate a essas plantas indesejáveis. O sorgo (Sorghum bicolor (L.) Moench) é uma gramínea forrageira com potencial alelopático por liberar aleloquímicos, especialmente a benzoquinona sorgoleone. Portanto, o objetivo deste trabalho foi avaliar o efeito alelopático da fração acetato de etila de sorgo sobre a germinação e o crescimento inicial de picão-preto e amendoim-bravo, verificando porcentagem de germinação, índice de velocidade de germinação, comprimento de plântulas, além das biomassas, fresca e seca, das plântulas. Os experimentos foram conduzidos no laboratório de botânica do Centro Universitário de Maringá Unicesumar, utilizando câmara de incubação B.O.D. a 25드 e fotoperíodo de 12 horas, durante quatro dias. Os tratamentos foram constituídos por diferentes concentrações da fração acetato de etila de sorgo (0, 250, 500, 750 e 1000 ppm). O delineamento experimental foi inteiramente casualizado, com cinco repetições, sendo, cada uma, constituída por 25 sementes distribuídas em placa de Petri. A fração reduziu a germinação e o crescimento inicial das plantas invasoras, constituindo-se em uma alternativa viável para diminuir o uso excessivo de herbicidas e impacto ambiental.
\end{abstract}

PALAVRAS-CHAVE: Alelopatia, Bidens pilosa L., Euphorbia heterophylla L.

\section{INHIBITION OF WEEDS BY ETHYL ACETATE FRACTION OF SORGO}

\section{ABSTRACT}

Wild poinsettia (Euphorbia heterophylla L.) and beggar-ticks (Bidens pilosa L.) are among the main weeds of the soybean crop (Glycine max (L.) Merril). The most used control method is the chemical, through herbicides, often applied indiscriminately with 
consequent environmental impact, as well as high cost. However, allelopathic interactions promoted by secondary metabolites released by plant cover may characterize an alternative means of combating these undesirable plants. Sorghum (Sorghum bicolor (L.) Moench) is a forage grass with allelopathic potential for releasing allelochemicals, especially benzoquinone sorgoleone. Therefore, the objective of this study was to evaluate the allelopathic effect of ethyl acetate fraction of sorghum on the germination and initial growth of beggar-ticks and wild poinsettia, checking percentage of germination, germination speed index, seedling length, besides biomass, fresh and dry, of the seedlings. The experiments were conducted at the Botanic Laboratory of University Center of Maringá - Unicesumar, using incubation chamber B.O.D. at $25^{\circ} \mathrm{C}$ and photoperiod of 12 hours, for four days. The treatments were constituted by different concentrations of the ethyl acetate fraction of sorghum $(0,250,500,750$ and $1000 \mathrm{ppm})$. The experimental design was completely randomized, with five replicates, each consisting of 25 seeds distributed in Petri dishes. The fraction reduced germination and initial growth of weeds, constituting a viable alternative to reduce the excessive use of herbicides and environmental impact.

KEYWORDS: Allelopathy; Bidens pilosa L., Euphorbia heterophylla L.

\section{INTRODUÇÃO}

A soja é uma cultura de grande importância econômica e, o Brasil, na safra 17/18, produziu 119 milhões de toneladas de sementes (CONAB, 2018). Contudo, o gasto com herbicidas é demasiado para combater plantas invasoras e melhorar as condições de crescimento das culturas. O controle destas plantas com herbicidas, embora efetivo, é bastante oneroso, além de aumentar os problemas ligados à saúde ambiental (YANG et al., 2004; DAYAN et al., 2009).

Nas últimas duas décadas, também aumentou o número de cultivares geneticamente modificadas, buscando diminuir a dependência do uso de herbicidas e pesticidas nas lavouras de soja, milho, canola e algodão (LLEWELLYN, 2018), devido ao uso excessivo de agrotóxicos e o impacto ambiental, além do aumento do número de espécies resistentes aos defensivos. Atualmente são encontradas 247 espécies resistentes a herbicidas, sendo 144 plantas dicotiledôneas e 103 monocotiledôneas, totalizando 157 herbicidas que apresentam resistência (HEAP, 2016).

Entre as principais plantas invasoras da cultura de soja e resistentes aos herbicidas, estão o Amendoim-bravo (Euphorbia heterophylla L.) e o Picão-preto (Bidens pilosa L.) (SPIASSI et al., 2015), sendo que E. heterophylla L. causa danos a diversas culturas como soja, milho, pastagem, banana, arroz, amendoim, feijão e cana-de-açúcar (ARESTRUP et al., 2008). Segundo Carvalho et al. (2010), essa espécie é agressiva e sua presença em áreas de cultivo de soja reduz a disponibilidade de macronutrientes e, consequentemente, o desenvolvimento da cultura, bem como a perda de produção.

De acordo com Vidal et al., (2007), o picão-preto (B. pilosa L.), proveniente da América Tropical, é uma espécie herbácea, autógama, com taxa de $9 \%$ de fecundação cruzada e dissemina-se apenas por sementes, com ciclo anual bastante curto para completar até três gerações por ano, sendo encontrada em todo território brasileiro e é considerada umas das principais plantas daninhas da região CentroSul do Brasil (LORENZI, 2008).

Segundo Gazziero et al., (1998), muitas espécies, como o picão-preto, são resistentes ao uso de herbicidas inibidores da enzima acetato lactato sintase. Esta é 
responsável pela catálise de uma das reações primárias da via metabólica de produção dos aminoácidos valina, leucina e isoleucina. Substâncias alelopáticas presentes no metabolismo secundário de espécies vegetais podem alterar importantes vias metabólicas ativas no processo de germinação e no desenvolvimento inicial de plântulas (BARBOSA et al., 2018). Weir et al. (2004) conceitua alelopatia como a capacidade de um organismo produzir metabólitos que atuam inibindo ou estimulando o crescimento ou o avanço de outros organismos que estão próximos.

O controle de plantas invasoras pode ser realizado através de alelopatia, sendo um método barato em comparação com outros não poluentes, e não requer o uso de equipamentos sofisticados para sua aplicação (OLIVEIRA, 2014).

Santos (2012) comprovou que o Sorgo (Sorghum bicolor (L.) Moench) é um forte combatente às invasoras. Esse cereal é cultivado em todo o mundo devido particularmente a sua alta produtividade e formação nutricional que é semelhante a do milho. Colabora para o controle dessas plantas indesejáveis por sua capacidade em produzir metabólitos secundários através dos tricomas de suas raízes (PEIXOTO; SOUZA, 2002).

A combinação de substâncias lipídicas, relacionadas a enzimas especializadas, são conhecidas como sorgoleone e são capazes de permanecerem presentes no solo por um período longo de tempo. Este exsudado, em quantidades consideráveis nos tricomas das raízes do sorgo, quando em contato com as plantas invasoras inibem seu crescimento por atuarem, principalmente, na inibição da via fotossintética (SANTOS et al., 2012).

As pesquisas alelopáticas vêm crescendo na área agrícola, entretanto, controlar as condições edafoclimáticas é um desafio para os pesquisadores e bioensaios laboratoriais proporcionam resultados mais confiáveis em relação aos efeitos alelopáticos. Portanto, este trabalho investigou os efeitos alelopáticos da fração acetato de etila do sorgo sobre a germinação e o crescimento inicial das plantas invasoras picão-preto (B. pilosa L.) e amendoim bravo (E. heterophylla L.).

\section{MATERIAL E MÉTODOS}

Foram conduzidos experimentos no laboratório de botânica do Centro Universitário de Maringá - UNICESUMAR, no período de ago/2016 a jul/2017, utilizando câmaras de incubação tipo B.O.D. para germinação e o crescimento inicial das plantas invasoras picão-preto (B. pilosa L) e amendoim bravo (E. heterophylla L.) na presença ou ausência da fração acetato de etila de sorgo (S. bicolor (L.) Moench).

\section{Obtenção da fração acetato de etila de sorgo}

Após partição líquido-líquido, com solventes orgânicos, foi obtida a fração acetato de etila de sorgo. Os tratamentos consistiram em diferentes concentrações desta fração $(0,250,500,750$, e 1000 ppm) e a diluição foi realizada com metanol/água $50 \%$.

\section{Material biológico}

As sementes das plantas invasoras picão-preto (B. pilosa L.) e amendoim bravo ( $E$. heterophylla L.) foram adquiridas comercialmente, em estabelecimento devidamente certificado. 


\section{Condução experimental}

Antes da instalação e avaliação de cada experimento, a bancada, a câmara incubadora, as mãos e os materiais foram desinfetados, e as sementes previamente selecionadas quanto ao tamanho e à forma, e então mergulhadas na solução de hipoclorito de sódio ( $\mathrm{NaClO}$ ) 2\%, por 1-2 minutos, sendo lavadas abundantemente com água destilada.

\section{Avaliação da germinação}

Foram distribuídas 25 sementes de picão-preto ou amendoim bravo em placa de Petri, contendo duas folhas de papel para germinação e adicionado $8 \mathrm{~mL}$ da fração acetato de etila em diferentes concentrações (0, 250, 500, 750, e 1000 ppm). Durante 24 horas, as placas de Petri permaneceram em repouso para a completa evaporação do metanol contido na fração. Foi realizado um controle em metanol, onde foram adicionados $8 \mathrm{~mL}$ metanol/água $50 \%$ na placa de Petri, e no controle em água foram adicionados $8 \mathrm{~mL}$ de água na placa de Petri.

Após semeadura, as placas de Petri foram acondicionadas em câmara de germinação do tipo B.O.D., com temperatura a $25^{\circ} \mathrm{C}$ e fotoperíodo de 12 horas, durante quatro dias.

Para a avaliação da germinação das sementes, foram realizadas contagens diárias durante o período de incubação e consideradas germinadas as sementes com protrusão radicular de $2 \mathrm{~mm}$, conforme descrito por Hartmann et al. (2001).

\section{Porcentagem de germinação (\% G)}

A porcentagem de germinação $(\% G)$ foi obtida pela representação da porcentagem de sementes germinadas em relação ao número de sementes dispostas a germinar sob as determinadas condições experimentais, dada por:

$\% \mathrm{G}=\left(\sum \mathrm{ni} \cdot \mathrm{N}^{1}\right) \cdot 100$

Onde: $\sum \mathrm{ni}=$ número total de sementes germinadas;

$\mathrm{N}^{1}=$ número de sementes dispostas para germinar.

\section{Índice de velocidade de germinação (IVG)}

O índice de velocidade de germinação (IVG) foi obtido utilizando a equação proposta por Ferreira e Borghetti (2004):

$\mathrm{IVG}=\mathrm{G} 1 / \mathrm{N} 1+\mathrm{G} 2 / \mathrm{N} 2+\ldots \mathrm{Gn} / \mathrm{Nn}$

Onde: $\mathrm{G}=$ número de sementes;

$\mathrm{N}=$ número de dias após a semeadura.

\section{Avaliação do crescimento inicial}

$\mathrm{O}$ crescimento inicial das plantas invasoras foi verificado a partir do comprimento da plântula, bem como das respectivas biomassas fresca e seca.

\section{Comprimento da plântula}

O comprimento das plântulas foi determinado entre o ápice aéreo e o ápice da raiz, sendo medido com o auxílio de régua milimetrada. Somente foram mensuradas as plântulas com capacidade de desenvolvimento (BRASIL, 2009). 


\section{Biomassa da plântula}

Após verificação do comprimento, foi imediatamente determinada a biomassa fresca das plântulas de picão-preto e amendoim bravo por meio da pesagem em balança analítica. Após a obtenção da biomassa fresca, as plântulas foram devidamente acondicionadas em sacos de papel e colocadas em estufa para secagem até peso constante a $60^{\circ} \mathrm{C}$, para obtenção da biomassa seca também por meio da pesagem em balança analítica (BORELLA; PASTORINI, 2009).

\section{Análise estatística}

O delineamento experimental utilizado foi inteiramente casualizado, com cinco repetições de cada tratamento. Os dados foram avaliados por análise de variância e as médias entre tratamentos comparados pelo teste Scott Knott a $5 \%$ de significância (SCOTT; KNOTT, 1974), utilizando o software SISVAR da Universidade Federal de Lavras - UFLA (FERREIRA, 2014).

\section{RESULTADOS E DISCUSSÃO}

A fração acetato de etila, em todas as concentrações analisadas $(0,250,500$, 750 e 1000 ppm), diminuiu significativamente crescimento inicial e a germinação de plântulas de B. pilosa L., reduzindo o comprimento das plântulas (figura 1) e biomassas fresca e seca (figura 2) e inibindo a porcentagem de germinação e o índice de velocidade de germinação (Tabela 1).

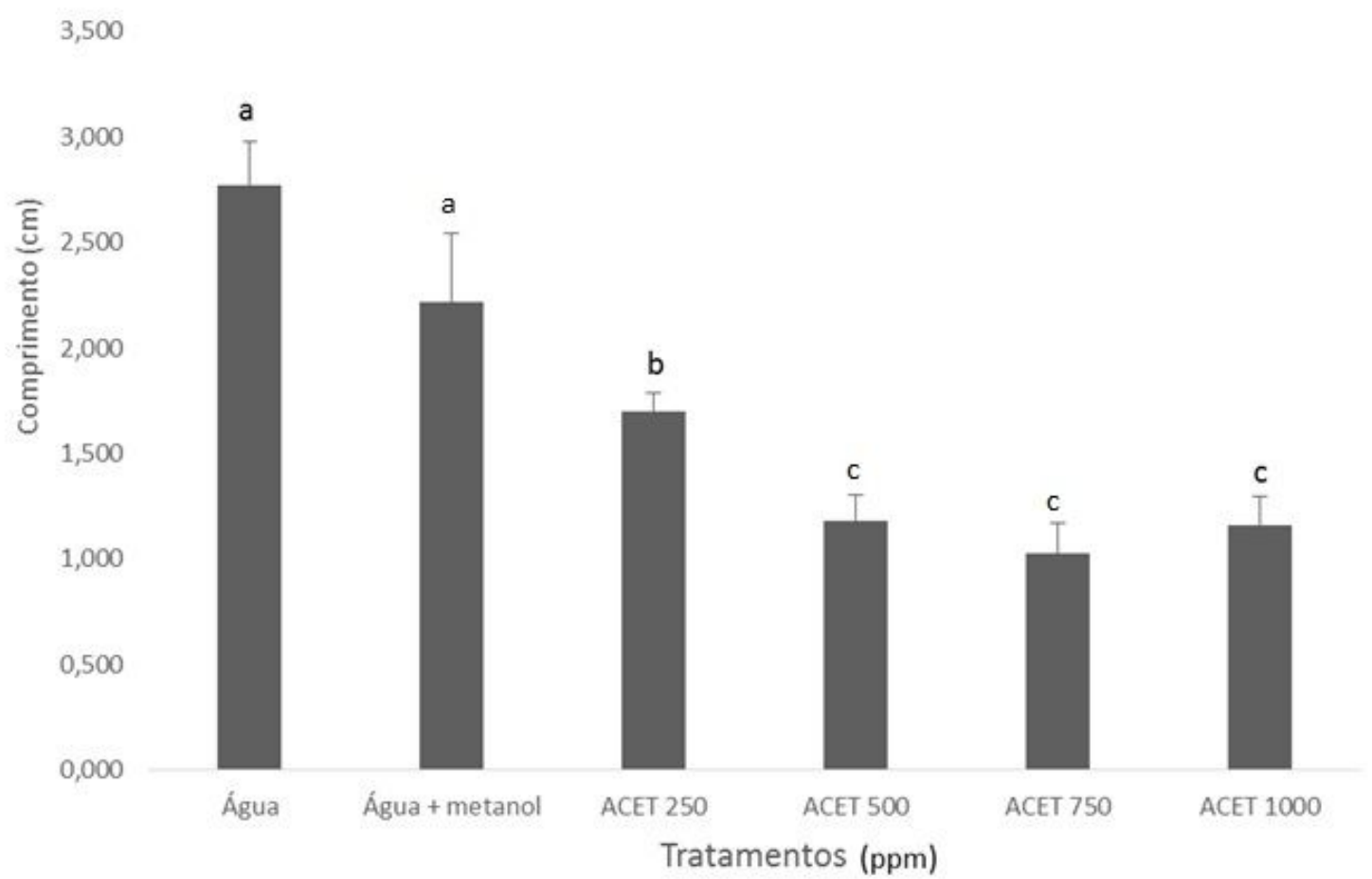

FIGURA 1. Comprimento de plântulas de B. pilosa L. tratadas com diferentes concentrações $(0,250$, 500,750 e 1000 ppm) da fração acetato de etila de sorgo. Os resultados estão indicados como média \pm erro padrão. Letras diferentes indicam diferenças estatísticas de acordo com o teste Scott-knott a $5 \%$ de significância. 


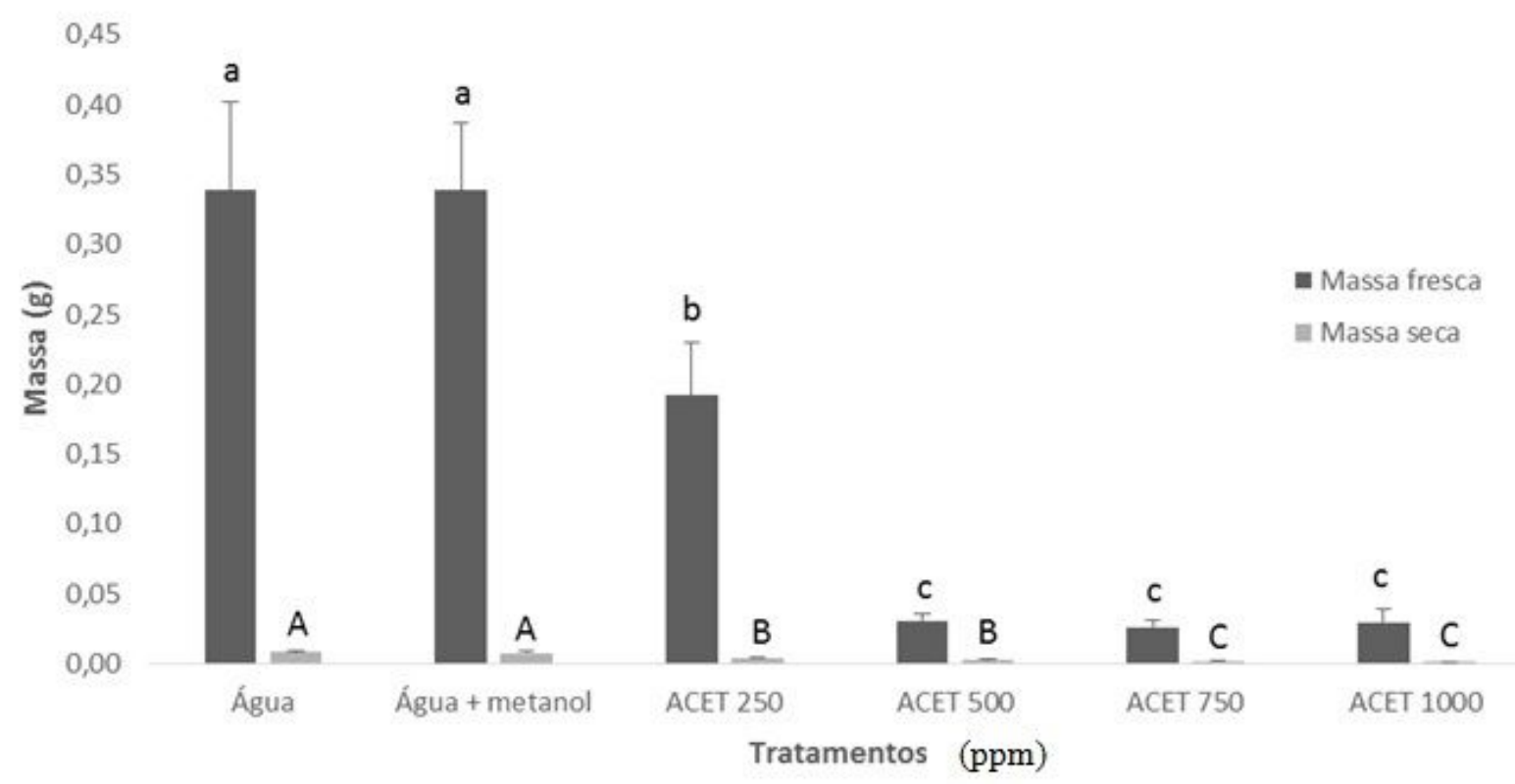

FIGURA 2. Biomassas fresca e seca, de plântulas de B. pilosa L. tratadas com diferentes concentrações $(0,250,500,750$ e 1000 ppm) da fração acetato de etila de sorgo. Os resultados estão representados como média \pm erro padrão. Letras diferentes indicam diferenças estatísticas de acordo com o teste Scott-knott a 5\% de significância

TABELA 1. Porcentagem de germinação (\%G) e índice de velocidade de germinação (IVG) de plântulas de B. pilosa L. tratadas com diferentes concentrações $(0,250,500,750$ e 1000 ppm $)$ da fração acetato de etila de sorgo. Os resultados estão representados como média \pm erro padrão.

\begin{tabular}{ccc}
\hline TRAT (ppm) & GERMINAÇÃO (\%) & IVG (\%) \\
\hline $\mathbf{H}_{2} \mathbf{O}$ & $76 \pm 4,899 \mathrm{a}$ & $12 \pm 0,887 \mathrm{a}$ \\
$\mathbf{H}_{\mathbf{2}} \mathbf{O}+$ METANOL & $73 \pm 1,414 \mathrm{a}$ & $10 \pm 1,135 \mathrm{a}$ \\
ACET 250 & $46 \pm 6,145 \mathrm{~b}$ & $10 \pm 1,251 \mathrm{~b}$ \\
ACET 500 & $17 \pm 2,653 \mathrm{C}$ & $4 \pm 0,631 \mathrm{C}$ \\
ACET 750 & $14 \pm 3,487 \mathrm{C}$ & $4 \pm 0,548 \mathrm{C}$ \\
ACET 1000 & $12 \pm 1,633 \mathrm{C}$ & $3 \pm 0,647 \mathrm{C}$ \\
\hline
\end{tabular}

*Letras diferentes indicam diferenças estatísticas de acordo com o teste Scott-knott a $5 \%$ de significância.

Os resultados observados nesta pesquisa confirmam os dados obtidos por Oliveira et al. (2019) que verificaram a atividade alelopática de diversos extratos e concluíram que o extrato de sorgo e braquiária foram os mais agressivos sobre o crescimento de picão-preto.

Olibone et al. (2006) verificaram que a palhada de sorgo no solo, onde foi cultivado soja, promoveu inibição do crescimento do sistema radicular desta cultura. Vidal (1995) também observou que a presença de palhada de sorgo no solo resultou em menores taxas de germinação e emergência de invasoras.

O sorgo produz a quinona sorgoleone, uma substância que inibe germinação e o crescimento de várias plantas e age diretamente no processo fotossintético. (FERREIRA; AQUILA, 2000). Souza et al. (1999) relataram que a sorgoleona, causou fitotoxidade sobre plantas de feijão, trigo, caruru e soja, reduzindo o porte e promovendo o murchamento dessas espécies. 
A sorgoleone e a 1,4-hidroquinona compõem cerca de $90 \%$ da secreção oleosa das raízes de sorgo, os $10 \%$ restantes da composição do exsudado de sorgo são de substâncias menores que, embora semelhantes ao sorgoleone, diferem em muitos casos no comprimento e no grau de saturação das cadeias alifáticas e na substituição do anel de quinona (CZARNOTA et al., 2001). A sorgoleone é amplamente conhecida como um inibidor do fotossistema II (PSII) muito bem documentado (NIMBAL et al., 1996)

Neste trabalho verificou-se também que as frações igual ou superior a 500 ppm de acetato de etila apresentaram um controle eficaz sobre $E$. heterophylla L., diminuindo o comprimento (figura 3), as biomassas fresca e seca (figura 4), bem como a germinação e o IVG (tabela 2).

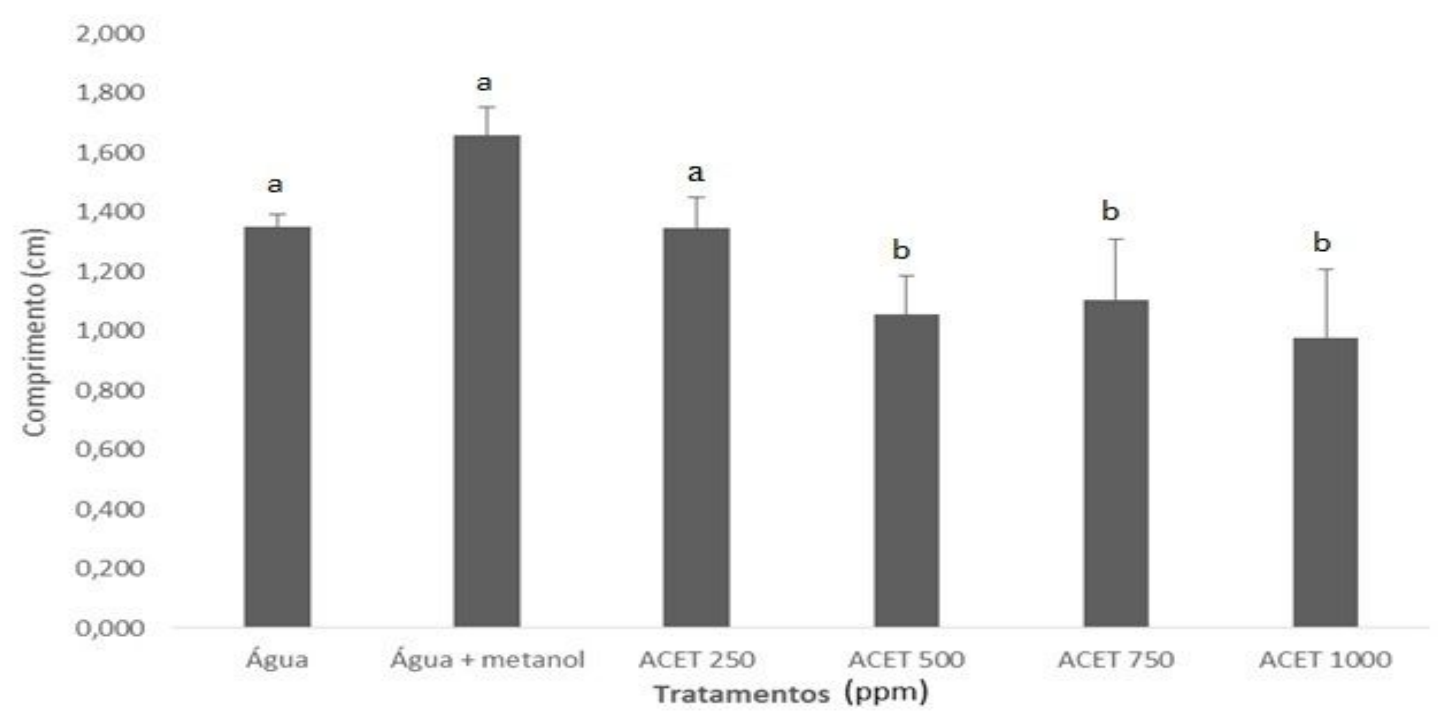

FIGURA 3. Comprimento de plântulas de E. heterophylla L. tratadas com diferentes concentrações $(0$, $250,500,750$ e 1000 ppm) da fração acetato de etila de sorgo. Os resultados estão representados como média \pm erro padrão. Letras diferentes indicam diferenças estatísticas de acordo com o teste Scott-knott a 5\% de significância.

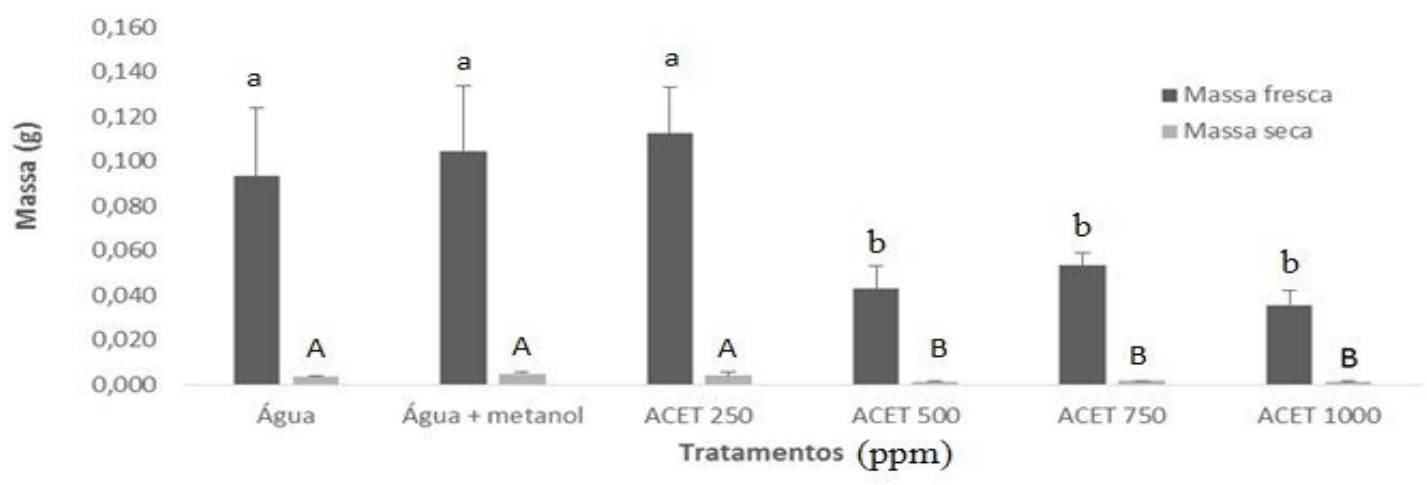

FIGURA 4. Biomassa seca e fresca de E. heterophylla L. tratadas com diferentes concentrações $(0$, $250,500,750$ e 1000 ppm) da fração acetato de etila de sorgo. Os resultados estão representados como média \pm erro padrão. Letras diferentes indicam diferenças estatísticas de acordo com o teste Scott-knott a $5 \%$ de significância. 
TABELA 2. Porcentagem de germinação (\%G) e índice de velocidade de germinação (IVG) de plântulas de E. heterophylla L. tratadas com diferentes concentrações $(0,250,500,750$ e 1000 ppm) da fração acetato de etila de sorgo. Os resultados estão representados como média \pm erro padrão.

\begin{tabular}{ccc}
\hline TRAT (ppm) & GERMINAÇÃO (\%) & IVG (\%) \\
\hline $\mathbf{H}_{2} \mathbf{O}$ & $30 \pm 3,830 \mathrm{a}$ & $5 \pm 1,029 \mathrm{a}$ \\
$\mathbf{H}_{2} \mathbf{O}+$ METANOL & $36 \pm 1,414 \mathrm{a}$ & $6 \pm 1,421 \mathrm{a}$ \\
ACET 250 & $25 \pm 1,497 \mathrm{a}$ & $6 \pm 0,536 \mathrm{a}$ \\
ACET 500 & $16 \pm 1,265 \mathrm{~b}$ & $4 \pm 0,731 \mathrm{a}$ \\
ACET 750 & $12 \pm 2,829 \mathrm{~b}$ & $3 \pm 0,772 \mathrm{~b}$ \\
ACET 1000 & $9 \pm 2,653 \mathrm{~b}$ & $2 \pm 0,520 \mathrm{~b}$ \\
\hline
\end{tabular}

*Letras diferentes indicam diferenças estatísticas de acordo com o teste Scott-knott a $5 \%$ de significância.

Alonso-Sánchez et al. (2017) notaram que o extrato aquoso de Sorghum halepense (L.) Pers. apresentou ação inibitória sobre a porcentagem de germinação de E. heterophylla L. Além de observar o efeito alopático do sorgo sobre plantas invasoras, são necessários também estudos que verifiquem seus efeitos sobre culturas anuais. Observações realizadas em lavouras de soja cultivadas após o sorgo mostraram efeito negativo no estabelecimento do estande das plantas e no desenvolvimento inicial, indicando interação prejudicial com os compostos alelopáticos liberados pela decomposição da palha do sorgo, como tanino, alguns ácidos orgânicos e graxos, entre outros (PEIXOTO; SOUZA, 2002).

A alelopatia, sob o ponto de vista agronômico, é de grande interesse, pois possibilita não só a seleção de plantas de pastagens que possam auxiliar no controle de determinadas espécies indesejáveis, como também, o estabelecimento de espécies de gramíneas e leguminosas forrageiras adequadas (WARDLE, 1987). Os aleloquímicos produzidos por uma planta podem influenciar a vegetação de um local, a sucessão de plantas, a indução de dormência e a preservação de sementes.

A alelopatia pode ser uma alternativa ao uso excessivo de agrotóxicos na produção agrícola que vem sendo um assunto muito debatido por órgãos públicos, ambientalistas e pela sociedade civil, pois resulta em fatores negativos como a degradação do meio ambiente. Os bio-herbicidas vêm cada vez mais constituindo um caminho para diminuição da utilização desses agentes químicos. Além de preservar o meio ambiente, diminui os custos de produção e reduz a contaminação gerada pelos resíduos químicos.

\section{CONCLUSÃO}

Os resultados indicam que o sorgo apresenta efeito bio-herbicida, auxiliando no controle de invasoras em sistemas agrícolas, demonstrando benefícios à cultura por desfavorecer a germinação e o crescimento inicial de picão preto e amendoim bravo. Entretanto, são necessários testes a campo para comprovar os resultados na produção e verificar também os efeitos nas culturas agrícolas.

\section{REFERÊNCIAS}

ARESTRUP, J. R.; KARAM, D.; CORRÊA, E. J. A.; FERNANDES, G. W. Análise da viabilidade de sementes de Euphorbia heterophylla. Planta Daninha, v. 26, n. 3, p. 515-519, 2008. Disponível em: http://dx.doi.org/10.1590/S010083582008000300006. DOI: 10.1590/S0100-83582008000300006. 
BARBOSA, J. A.; FERREIRA, S. D.; SALVALAGGIO, A. C.; COSTA, N. V.; ECHER, M. M. Allelopathy of aqueous Pachyrhizus erosus L. extracts on Euphorbia heterophylla and Bidens pilosa. Pesquisa Agropecuária Tropical , Goiânia, v. 48, n. 1, p. 59-65, 2018. Disponível em: http://dx.doi.org/10.1590/198340632018v4851117. DOI: 1 0.1590/1983-40632018v4851117.

BRASIL, Ministério da Agricultura e da Reforma Agrária. Regras para análise de sementes. Brasília: Coordenação de Laboratório Vegetal, Departamento de Defesa Vegetal, 398p. Brasileira Botânica, São Paulo, v. 32, n.1, p. 183-188, 2009. Disponível em: http://www.agricultura.gov.br/assuntos/insumosagropecuarios/arquivos-publicacoes-insumos/2946_regras_analise_sementes.pdf

BORELLA, J.; PASTORINI, L.H. Influência alelopática de Phytolacca dioica L. na germinação e crescimento inicial de tomate e picão-preto. Biotemas, Florianópolis, v.22, n.3, p.67-75, 2009. Disponível em: https://doi.org/10.5007/21757925.2009v22n3p67. DOI: 10.5007/2175-7925.2009v22n3p67.

CARVALHO, L. B.; BIANCO, S.; GUZZO, C. D. Interferência de Euphorbia heterophylla no crescimento e acúmulo de macronutrientes da soja. Planta daninha, v. 28, n. 1, p. 33-39, 2010. Disponível em: http://dx.doi.org/10.1590/S010083582010000100004. DOI: 10.1590/S0100-83582010000100004.

CZARNOTA, M. A.; PAUL, R. N.; DAYAN, F. E.; NIMBAL, C. I.; WESTON, L. A. Mode of action, localization of production, chemical nature, and activity of sorgoleone: a potent PSII inhibitor in Sorghum spp. root exudates. Weed Technology. v.15, p.813-825, 2001. Disponível em: https://www.jstor.org/stable/3988565?seq=1\#metadata_info_tab_contents.

CONAB - Companhia Nacional de Abastecimento. Acompanhamento da safra brasileira: grãos. Safra 2018/19. v.6. n.1. 2018. Disponível em: https://www.conab.gov.br/info-agro/safras/graos.

DAYAN, F.E.; HOWELL, J.L.; WEIDENHAMER, J.D. Dynamic root exudation of sorgoleone and its in planta mechanism of action. Journal of Experimental Botany, v.60, n.7, p.2107-2117, 2009. Disponível em: https://www.ncbi.nlm.nih.gov/pmc/articles/PMC2682501/. DOI: 10.1093/jxb/erp082.

FERREIRA, A. G., AQUILA, M. E. A. Alelopatia: Uma Área Emergente da Ecofisiologia. Revista Brasileira de Fisiologia Vegetal, 12, p. $175-204,2000$. Disponível em: http://www.lpv.esalq.usp.br/sites/default/files/8\%20\%20Semana\%204\%20-\%20Alelopatia\%20na\%20agricultura\%20\%20referencia\%20leitura\%20-\%20referencia\%20leitura.pdf.

FERREIRA, A. G.; BORGHETTI, F. (Ed.). Germinação: do básico ao aplicado. Porto Alegre: Artmed, p. 323, 2004.

FERREIRA, D. F. Sisvar: a Guide for its Bootstrap procedures in multiple comparisons. Ciência e agrotécnogia , [online],vol.38, n.2, p. 109-112, 2014. Disponível em: <http://dx.doi.org/10.1590/S1413-705420114000200001>. DOl: 10.1590/S1413-70542014000200001. 
GAZZIERO, D.P.; BRIGHENTI, A.M.; MACIEL, G.D.; CHRISTOFFOLETI, P.J.; ADEGAS, F.S.; VOLL, E. Resistência de amendoim-bravo aos herbicidas inibidores da enzima ALS. Planta Daninha, Botucatu, v.16, n.2, p.117-125, 1998. Disponível em: http://dx.doi.org/10.1590/S0100-83581998000200005. DOI: 10.1590/S010083581998000200005 .

HARTMANN, T. H.; KESTER, D. E.; DAVIES, J. R. F. T.; GENEVE, R. Plantpropagation: principles and practices. 7 ed. New York: Prentice Hall, p, 880, 2001.

HEAP, I. International survey of herbicide resistant weeds. Disponível em: www.weedscience.org/ln.asp. Acesso em: 20 fev. 2016.

LLEWELLYN, D. Does Global Agriculture Need Another Green Revolution? Engineering. v. 4. p. 449-451, 2018.

LORENZI, H. Plantas daninhas do Brasil: terrestres, aquáticas, parasitas e tóxicas. 4. ed. São Paulo: Instituto Plantarum, 640 p. 2008.

NIMBAL, C.I. ; YERKES, C.N.; WESTON, L.A.; WELLER, S.C. Herbicidal activity and site of action of the natural product sorgoleone. Pesticide Biochemistry and Physiology, v.54, n.11, p.73-83, 1996. Disponível em: https://doi.org/10.1006/pest.1996.0011. DOI: 10.1006/pest.1996.0011

OLIBONE, D., CALONEGO, J.C., PAVINATO, P.S. E ROSOLEM, C.A. Crescimento Inicial Da Soja Sob Efeito De Resíduos De Sorgo. Planta Daninha, Viçosa-MG, v. 24, n. 2, p. 255-261, 2006. Disponível em: http://dx.doi.org/10.1590/S010083582006000200007. DOI: 10.1590/S0100-83582006000200007.

OLIVEIRA, J. S. Potencial alelopático em girassol e em braquiária. Dissertation (Mestrado em Recursos Genéticos Vegetais) - Universidade Federal do Recôncavo da Bahia, Cruz das Almas, Bahia, 2014.

OLIVEIRA, J. S.; PEIXOTO, C. P.; LEDO, C. A. S.; ALMEIDA, A. T. Aqueous plant extracts in the control of Bidens pilosa L. Arquivo do instituto Biologico , v.86, p.16, 2019. Disponível em: http://dx.doi.org/10.1590/1808-1657000532016. DOI: 10.1590/1808-1657000532016.

PEIXOTO, M.F.; SOUZA, I.F. Efeitos de doses de imazamox e densidades de sorgo (Sorghum bicolor (L.) Moench) em soja (Glycine Max (L.) Merril) sob plantio direto. Ciência e Agrotecnologia, v.26, n.2, p.252-258, 2002.

ALONSO-SÁNCHEZ, L.; CASTELLANOS-GONZÁLEZ, L., ORTEGA-MESEGUER, I., MARTÍNEZ-PÉREZ, E. Efecto alelopático de un extracto acuoso de Sorghum halepense (L.) Pers sobre dos dicotiledóneas. Revista Científica

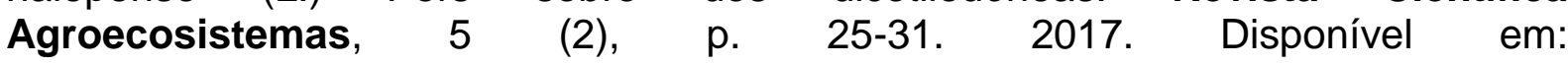
https://aes.ucf.edu.cu/index.php/aes/article/view/117/154.

SANTOS, I. L. V. L.; SILVA, C. R. C.; SANTOS, S. L.; MAIA, M. M. D. Sorgoleone: benzoquinona lipídica de sorgo com efeitos alelopáticos na agricultura como 
herbicida. Arquivo Instituto Biologico., São Paulo, v.79, n.1, p.135-144, jan./mar., 2012. Disponível em: http://dx.doi.org/10.1590/S1808-16572012000100020. DOI: 10.1590/S1808-16572012000100020.

SANTOS, V. H. M. Potencial alelopático de extratos e frações de Neea theifera Oerst. (Nyctaginaceae) sobre sementes e plântulas de Lactuca sativa. 2012. 251f. Dissertação (Mestrado em Ciências Biológicas - Ecofisiologia) - Instituto de Biociências de Botucatu; Universidade Estadual Paulista, Botucatu, SP, 2012. Disponível em: http://www.ibb.unesp.br/posgrad/teses/botanica_me_2012_valter_santos.pdf

SCOTT, A.; KNOTT, M. Cluster-analysis method for grouping means in analysis of variance. Biometrics, 30, 507-512, 1974. Disponível em: https://www.ime.usp.br/ abe/lista/pdfXz71qDkDx1.pdf. DOI: 10.2307/2529204.

SOUZA, C. N.; SOUZA, I. T.; PASQUAL, M. Extração reação de sorgoleone sobre o crescimento de plantas. Ciência e Agrotecnologia, Lavras, v.23, n.2, p.331338,1999. Disponível em: https://docplayer.com.br/60203026-Extracao-e-acao-desorgoleone-sobre-o-crescimento-de-plantas-1.html.

SPIASSI, A.; NÓBREGA, L. H. P; ROSA, D. M.; PACHECO, F. P.; SENEM, J.; PICCOLO DE LIMA, G. Allelopathic effects of pathogenic fungi on weed plants of soybean and corn crops. Bioscience Journal, Uberlândia, v. 31, n. 4, p. 10371048, $2015 . \quad$ Disponível em: https://www.researchgate.net/publication/281229736_Allelopathic_effects_of_pathog enic_fungi_on_weed_plants_of_soybean_and_corn_crops. DÖ: $10.14393 / \mathrm{BJ}-$ v31n4a2015-26142.

VIDAL, R. A. Amount of crop residues in no-till farming affects weed-crop ecosystems. Thesis (Ph.D.) - Purdue University, West Laffayete. 161 f. 1995. Disponível em: https://docs.lib.purdue.edu/dissertations/AAl9601598/.

VIDAL, R. A.; NUNES, A. L.; RESENDE, L. V.; LAMEGO, F. P.; SILVA, P. R. Análise genética de genótipos de Bidens pilosa através da técnica RAPD. Scientia Agraria, v.8, n.4, p.399-403, 2007. Disponível em: < https://revistas.ufpr.br/agraria/article/view/9887/8062>. DOI: http://dx.doi.org/10.5380/rsa.v8i4.9887.

WARDLE, D.A. Allelopathic in New Zealand pasture grassland ecosystem. N. Z. J. Experimental Agriculture , v.15, p.243-255, 1987. Disponível em: https://doi.org/10.1080/03015521.1987.10425567. 10.1080/03015521.1987.10425567.

WEIR, T. L.; PARK, S. W.; VIVANCO, J. M. Biochemical and physiological mechanisms mediated by allelochemicals. Current Opinion in Plant Biology 7: 472-479, 2004. Disponível em: https://doi.org/10.1016/j.pbi.2004.05.007. DOI: 10.1016/j.pbi.2004.05.007.

YANG, X.; SCHEFFLER, B. E.; LESLIE, A. Weston SOR1, a gene associated with bioherbicide production in sorghum root hairs. Jornal of Experimental Botany, v.55, n.406 p.2251-2259, 2004. Disponível em: https://doi.org/10.1093/jxb/erh252. DOI: $10.1093 / j x b / e r h 252$. 